\title{
A CAVALARIA MEDIEVAL IBÉRICA
}

\section{THE IBERIAN MEDIEVAL CHIVALRY}

Planejamos esse dossiê temático pretendendo reunir estudos sobre as cavalarias ibéricas, em suas múltiplas formas de interação social e política, sem esquecer das Ordens de cavalaria que apareceram em solo peninsular ou que a ela se referiam. Ao pensarmos em cavalaria na Península Ibérica, entre tantas fontes, chamam a nossa atenção as informações que podemos extrair da obra de Alfonso X, o sábio (1252-1284), dentre elas, aquela que ficou conhecida como Las Siete Partidas ${ }^{2}$.

O Título XXI da Segunda Partida trata da cavalaria, especificando, na primeira lei, que ser cavaleiro não é uma condição de nascimento e sim, o reconhecimento de uma série de características que fazem com que seu portador possa ser escolhido para pertencer a esse estamento.

Segundo Alfonso, houve alterações quanto à forma de se designar aqueles que, no seu tempo, integravam a cavalaria. Antigamente, segundo o rei, chamavam de milícia as companhias constituídas por homens escolhidos para desempenhar trabalhos em proveito de $\operatorname{todos}^{3}$. Na mesma lei, especifica-se que, na Espanha, os homens que integravam a cavalaria recebiam o nome de cavaleiros, pois "es mas honroso ir a caballo que en outra

\footnotetext{
${ }^{1}$ Professor na Universidade Federal de Alfenas (UNIFAL-MG).

2 ALFONSO X. Las Siete Partidas. Estractadas por el Licenciado D. Ignacio Velasco Perez. Madrid: Imprenta de los Señores Viuda de Jordan é Hijos Editores, 1843. Edición del 2010, p. 172-177.

${ }^{3}$ Por todos devemos entender aqueles que integravam o povo e esse, é entendido por Alfonso X, como a totalidade de um corpo social ligado por obrigações mútuas (MARQUEZ DE VILLANUEVA, 2004, p. 38).
} 
bestia”. Aqueles que são, portanto, escolhidos para essa função são mais honrados que os demais defensores, uma vez que existiam diversos tipos de defensores, porém nem todos atuavam a cavalo e, mesmo entre aqueles que faziam isso, nem todos detinham as qualidades que possibilitavam a eles serem escolhidos e serem, como tal, nomeados cavaleiros.

Para tanto, a primeira condição era ser nascido em boa linhagem, porém possuir essa característica não era tudo, pois havia outros impeditivos, entre eles a pobreza e os defeitos físicos. A pobreza dificultava e até mesmo impedia de exercer a sua função e os defeitos físicos impediam o uso das armas. Além desses impedimentos, existiam outros que impossibilitavam alguém, de boa linhagem, ser feito cavaleiro, uma vez que também estavam impedidos de serem escolhidos para cavaleiros os mercadores, os que eram acusados de traição, os pérfidos e aqueles acusados pelo delito de morte que ainda não haviam sido julgados e perdoados. Além desses, também estavam impedidos aqueles que, por escárnio, haviam sido nomeados cavaleiros por alguém que não dispunha de autoridade para isso. Somente aquele que era cavaleiro detinha a autoridade para fazer um cavaleiro.

Sendo livre dos impedimentos mencionados, necessitava ser portador de quatro virtudes: sanidade, fortaleza, moderação e justiça. Com a primeira e a segunda, expressavam as condições para proteger o rei, sendo fortes naquilo que viessem a fazer; com a terceira, não corriam o risco de se excederem nas ações que realizariam e, com a quarta, seriam justos nas decisões a serem tomadas. Por serem portadores de tais virtudes, saberiam usá-las nas atuações do cotidiano, sendo, portanto, diferentes dos demais, expressando dessa forma a posição que ocupavam na hierarquia social. Posição que implicava deveres para com o seu senhor, entre eles, não ter dúvida de protegê-lo e de morrer por ele, se assim fosse necessário. A lealdade para com seu senhor era condição fundamental da sua existência. Para assegurar que cumprissem com essas funções, duas medidas foram criadas. A primeira consistia em marcas feitas no braço direito com ferro quente, marcas que somente eles poderiam ter; a segunda era expressa pelo fato de escreverem os seus nomes no livro, onde se escreviam os nomes dos demais cavaleiros e de suas linhagens e ainda a localidade de onde provinham. Por meio dessas medidas, julgavam que não tinham como fugir das responsabilidades se viessem a cometer algum delito. 
A lembrança da condição assumida no momento em que foram feitos cavaleiros e a rígida conduta expressa pela lealdade ao seu senhor, juntamente com a prática das quatro virtudes, tornavam-nos dignos de serem respeitados e honrados. Somente em virtude de um mandato do rei ou da justiça poderia acontecer algo que os colocassem em situação de inferioridade. O pertencimento à cavalaria era fator de distinção entre os fidalgos, dando àqueles considerados como cavaleiros certas primazias em relação aos demais. Entre elas, os juristas destacaram as seguintes: se algum cavaleiro fosse acusado de ter cometido algum delito, pelo qual havia outros suspeitos, primeiro deveriam investigar a esses. O cavaleiro somente seria investigado se a acusação fosse sobre traição ao seu rei ou ao reino; enquanto estivessem ausentes de suas casas em campanhas ao serviço do seu rei ou ao seu mandato, não poderiam perder nenhuma de suas posses. Se alguém as tomasse, poderiam requerer a restituição a partir do dia em que voltassem para suas casas até quatro anos.

Se de uma parte os cavaleiros tinham os privilégios, por outra, o rigor na punição recebida era rigorosa e exemplar, caso fossem julgados culpados. Por motivo de traição ao rei ou ao reino, poderiam ser condenados a morrer de fome ou a terem a cabeça cortada. Para aqueles que fossem julgados e condenados por roubo, morte ou traição, o castigo poderia ser o lançamento ao mar ou às feras, conforme a tradição deixada pelos antigos. Porém, antes de receberem o castigo fatal, encontravam a desonra deixando de ser um cavaleiro. Para tanto, a mando do rei, um escudeiro colocava-lhe as esporas e cingia-lhe a espada. Feito isso, as correias que prendiam as esporas e a espada ao corpo do, ainda, cavaleiro eram cortadas, simbolizando a destituição da honrosa condição.

O Título XXI da Segunda Partida, ao apresentar, em forma de lei, especificidades referentes à cavalaria, especificamente à lealdade que ela deve demonstrar ao seu superior, enfatizando em vários momentos que esse é o rei e, também, ao estabelecer que o rei é quem concede a honraria da cavalaria, criou vários problemas entre a monarquia e a nobreza, uma vez que impedia que os primeiros nomeassem seus cavaleiros e, portanto, criassem o seu grupo particular. A ideia de cavaleiro presente na Segunda Partida reflete o pensamento de Alfonso X, que considerava a monarquia como a condutora do reino e a cavalaria como um corpo que lhe era leal e tanto a protegia como agia sob seu comando.

Embora a legislação contida nas Partidas somente começasse a entrar em vigor no reinado de Alfonso XI (1311 a 1350; coroado em 1331 como rei de Castela), encontramos 
nela e na referência à Cavalaria o desejo unificador da monarquia, em tempos do rei Sábio, que, ao suprimir prerrogativas até então também desempenhadas pela nobreza (por exemplo, armar cavaleiros), gerava uma série de conflitos a serem solucionados em tempos futuros.

Este dossiê foi planejado para colaborar com a produção e a divulgação de pesquisas relativas à Cavalaria na Península Ibérica, nas suas diversas manifestações: seu processo de formação e o estabelecimento dos meios de garantir a manutenção e a memória das ações da(s) cavalaria(s) em prol delas mesmas, das comunidades com as quais se relacionavam, bem como das monarquias Ibéricas.

No artigo "Modelo Cavaleiresco de dom Juan Manuel e Cavalaria Castellanoleonesa na passagem do século XIII para o XIV”, Olga Pisnitchenko analisa traços referentes à cavalaria presentes em obras elaboradas nos séculos XIII e XIV destacando continuidades e alterações pelas quais passou o modelo cavaleiresco no decorrer desses séculos.

Em "La imagem Póstuma del Caballero en la Castilla Bajo medieval: metonímias de su condición”, Marta Cendón Fernández apresenta-nos a relação entre a cavalaria e a nobreza e, na sequência, trata das atividades desenvolvidas pelos cavaleiros. Como objeto específico analisa a arte funerária presente em sepulcros de cavaleiros nos quais se encontram símbolos e cenas cuja análise enriquece conhecimento sobre a cavalaria.

"Entre cavaleiros e Pícaros: Literatura e sociedade Espanhola da Idade Média ao Renascimento", Katia Aparecida da Silva Oliveira, a partir de análise comparativa de obras da literatura espanhola do medievo ao renascimento, apresenta-nos traços da realidade social e histórica do período que, se por um lado tratou do cavaleiro, por outro também destacou o personagem pícaro, o oposto do cavaleiro.

Federico Javier Asiss González, a partir da análise de obras de Dom Juan Manuel, apresenta-nos, no artigo "La identidad gastronómica del noble castellano en los escritos manuelinos", os ensinamentos transmitidos por Dom Juan referentes às maneiras com que se deve comer e beber, destacando, por um lado, a recomendação manuelina para o comedimento cavaleiresco e, por outro, investigando o sentido de poder contido no gesto de oferecer banquetes.

Em "Dinâmicas da argumentação régia na dissolução da Ordem do Templo e na criação da Ordem de Cristo. Um esforço interpretativo (1307/08-1319)", Fabiano

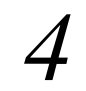


Fernandez, a partir da análise de cartas de sentença e da documentação do Concílio de Vienne (1311-1312), dentre outros documentos, questiona a visão harmônica presente na historiografia portuguesa referente à dissolução da Ordem do Templo.

Apesar de circunscrita a uns poucos aspectos da Cavalaria Ibérica, acreditamos que este dossiê temático ora publicado na Signum Revista da ABREM vem ressaltar a maturidade das investigações mais recentes e, ao mesmo tempo, fornecer ao público motivos para prosseguir o debate. 